\title{
Olahraga Bagi Orang yang Sibuk Di Kantor
}

\author{
Oleh: Yudik Prasetyo \\ Staf Pengajar Fakultas Ilmu Keolahragaan, UNY
}

\section{Pendahuluan}

Pada era globalisasi ini, orang semakin disibukan dengan berbagai pekerjaan untuk memenuhi kebutuhan hidupnya. Bekerja merupakan kebutuhan dan tuntutan yang harus dijalankan. Banyak orang yang bekerja dengan giat agar memperoleh penghasilan yang luar biasa, namun mereka lupa akan kesehatan. Tidak ada waktu untuk berolahraga adalah salah satu permasalahan yang banyak dihadapi para pekerja kantoran pada umumnya.Para pekerja kantor selalu pergi di pagi hari, dan pulang di malam hari akhirnya derajat kesehatan semakin menurun.

Untuk mencapai derajat kesehatan diperlukan ketekunan dalam menjalani kehidupan. Hidup aktif merupakan magnet menarik sejumlah kebiasaan yang jika dilihat satu per satu terlalu sederhana untuk dinilai. Namun secara kolektif, kebiasaan tersebut menjadi harapan utama demi kesehatan pribadi dan vitalitas, bahkan integritas kesehatan bangsa (Suharjana, 2004: 1-2).Berolahraga merupakan hal yang sangat penting bagi kehidupan manusia. Hal ini dikarenakan banyaknya manfaat yang dapat diperoleh dengan berolahraga. Berolahraga secara rutin dapat meningkatan ketahanan tubuh, jika daya tahan tubuh meningkat, maka manusia akan terhindar dari berbagai macam penyakit.

Sehat adalah nikmat karunia yang diberikan Allah SWT, yang menjadi dasar bagi segala nikmat dan kemampuan. Seseorang dapat merasakan bahwa nikmatnya makan, minum, tidur, serta kemampuan bergerak, bekerja, dan berfikir, akan berkurang atau bahkan hilang dengan terganggunya kesehatan. Untuk itu, orang yang sesibuk apapun, harus senantiasa mensyukuri nikmat sehat karunia Allah SWT dengan memelihara dan meningkatkan melalui berbagai upaya, diantaranya yang terpenting, termurah dan fisiologis yaitu melalui olahraga (Santosa Giriwijoyo dan Muchtamadji M.A, 2006: 8). Sebenarnya, untuk memulai olahraga sangat mudah, seperti kata Aa Gym, cukup 3M, mulai dari diri sendiri, mulai dari yang ringan/kecil, dan mulai dari sekarang (Dhiah A.P., 2012).

\section{Dampak bagi Orang yang Tidak Pernah Berolahraga}

Olahraga yang dilakukan secara teratur, terukur, dan berkelanjutan akan memberikan manfaat bagi tubuh kita, namun seseorang yang tidak pernah berolahraga akan mendapatkan 
dampak yang merugikan. Ketika otot dan rangka tubuh bergerak, denyut jantung akan meningkat sehingga darah beserta oksigen dan nutrisi yang dibawanya akan terdistribusi dengan baik. Mekanisme tersebut tidak terjadi apabila tubuh tidak olahraga. Tidak bergerak seharian akan menyebabkan bagian-bagian tertentu dari tubuh mengalami tekanan yang konstan, sehingga akan mengakibatkan gangguan saraf dan memicu berbagai keluhan ringan. Tidak berolahraga juga berdampak pada distribusi cairan limpa. Tidak seperti darah yang memiliki jantung sebagai pemompa, limpa sangat tergantung pada gerakan otot untuk dapat didistribusikan ke berbagai jaringan tubuh (http://www.fk.unair.ac.id/news/kilasan/akibattidak-pernah-olahraga-html).

Orang yang tidak pernah berolahraga mempunyai beberapa ciri kesamaan. Ciri-ciri fisik orang yang tidak pernah berolahraga yaitu sebagai berikut:

a. Terjadinya penumpukan lemak di beberapa daerah tubuh, terutama di bagian perut, lengan dan paha

b. Tubuh tidak terlihat kencang, tetapi lembek atau bergelambir

c. Wajah terlihat lesu dan kurang bergairah

d. Sering mengeluh mengantuk di pagi hari

e. Mudah lelah atau napas tersengal-sengal saat harus berjalan jauh atau naik turun tangga

f. Sering mengalami gangguan otot seperti kram atau kaku

Sumber: Vera Farah Bararah, 2011, http://m.detik.com/health/read/2011.

Badan kesehatan Dunia (WHO) menyebutkan sekitar dua juta orang di seluruh dunia meninggal karena penyakit akibat gaya hidup malas dan kurang berolahraga. Penelitian yang dilakukan oleh University of Hong Kong menyebutkan dampak jangka panjang dari tidak pernah berolahraga sama berbahanya dengan merokok. Penelitian yang dilakukan pada tahun 2004 tersebut, menyebutkan bahwa sekitar $20 \%$ penyebab kematian orang dewasa berusia 35 tahun ke atas adalah karena kurang olahraga (http://dokita.co/blog/bahaya-kurangberolahraga/).

Dampak yang timbul akibat tidak pernah berolahraga tidak hanya sebatas fisik saja, tetapi yang lebih ganas lagi bagi orang yang tidak mau aktif bergerak yaitu mudah terserang berbagai penyakit, seperti jantung koroner, tekanan darah tinggi, diabetes miletus, stroke, dll.

\section{Olahraga bagi Orang yang Sibuk di Kantor}

Para peneliti menemukan bahwa melakukan olahraga yang dilakukan secara intensif selama 2,5 menit memiliki manfaat sama dengan berlari selama 1,5 jam.Olahraga intensif ini yaitu melakukan lari secepat mungkin (sprint) selama 30 detik, diberi jeda istirahat sebentar, 
kemudian diulangi sebanyak 4 kali. Sturat Gray, seorang peneliti dari Universitas Aberdeen mengatakan bahwa olahraga tersebut lebih cepat untuk menekan tingkat kadar lemak daripada olahraga biasa selama 30 menit.Penelitian dilakukan dengan melibatkan banyak orang yang ditugaskan untuk melakukan olahraga intensif 2 menit di waktu pagi hari. Pada eksperimen yang dilakukan, peserta diperintahkan mengkonsumsi makanan berlemak seperti: roti, keju, mayonaise, kemudian pada pagi harinya peneliti melakukan pengecekan terhadap tingkat gula darah. Hasil yang didapat kadar lemak darah para peserta mengalami penurunan hingga 33 persen. Tingkat penurunan setara dengan hasil berlari selama 90 menit atau 1,5 jam (http://tipsehat4u.blogspot.com/2012).

Olahraga lain yang dapat dilakukan bagi orang sibuk, sebagai contoh dapat mengikuti gerakan-gerakan sebagai berikut:

Gerakan 1, side neck stretches:

Tujuan : untuk membantu mengurangi kekakuan pada bagian leher.

Gerakan ini cocok bagi seseorang yang pekerjaannya melibatkan posisi kepala menghadap satu arah terus menerus, misalnya di depan komputer.

Cara pelaksanaan:

a. Duduk dengan posisi punggung tegak

b. Posisi kaki ditekuk rileks, selebar bahu

c. Miringkan leher ke arah pundak secara perlahan, dan tahan selama 10 detik

d. Lakukan gerakan untuk kedua sisi.

e. Ulangi gerakan 8-10 kali

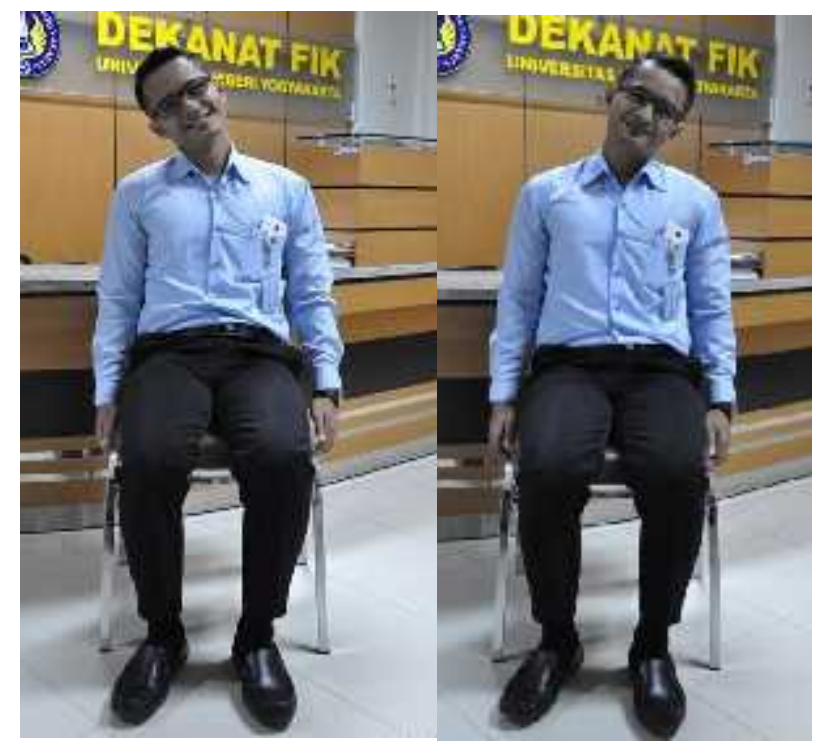

Gambar 1. Side neck stretches 
Gerakan 2, shoulder shrug

Tujuan : untuk membantu mengurangi kekakuan pada bagian bahu dan pundak.

Cara pelaksanaan:

a. Duduk dengan punggung tegak

b. Posisi kaki ditekuk rileks, selebar bahu

c. Angkat pundak ke arah atas hingga mendekati telinga, dan tahan selama 3-5 detik.

d. Turunkan kembali pundak ke posisi normal.

e. Ulangi gerakan hingga 8-10 kali.

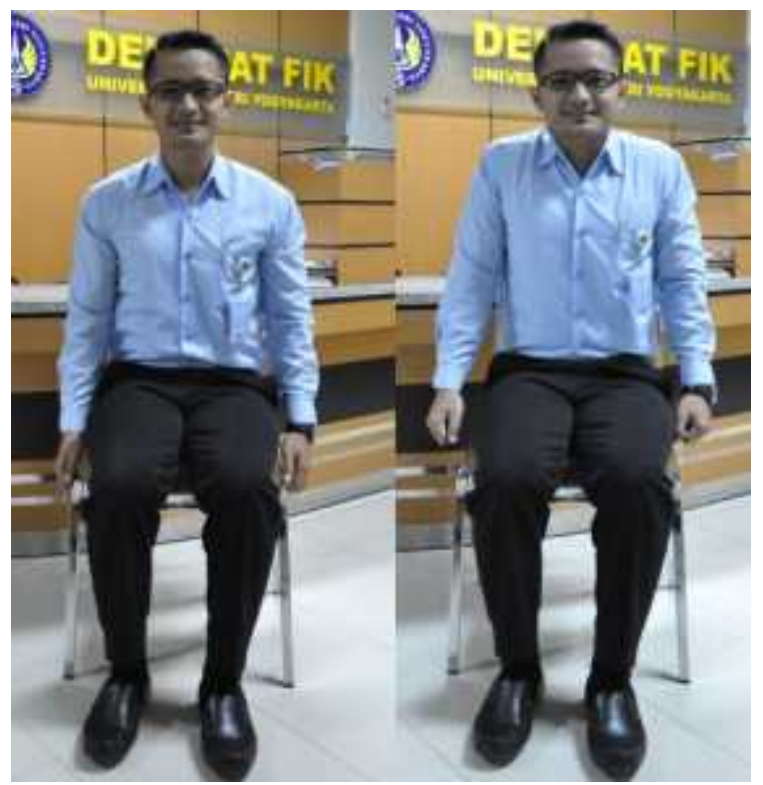

Gambar 2. Shoulder shrug

Gerakan 3, back side-stretch:

Tujuan : untuk membantu mengurangi kekakuan, pegal pada bagian punggung dan bahu setelah lama duduk saat bekerja.

Cara pelaksanaan:

a. Duduk dengan punggung tegak

b. Posisi kaki ditekuk rileks, selebar bahu

c. Angkat kedua tangan lurus ke atas dengan kedua telapak tangan saling berkaitan.

d. Miringkan tubuh ke arah kiri dan kanan secara perlahan untuk melakukan peregangan otot bagian punggung.

e. Ulangi gerakan 8-10 kali 


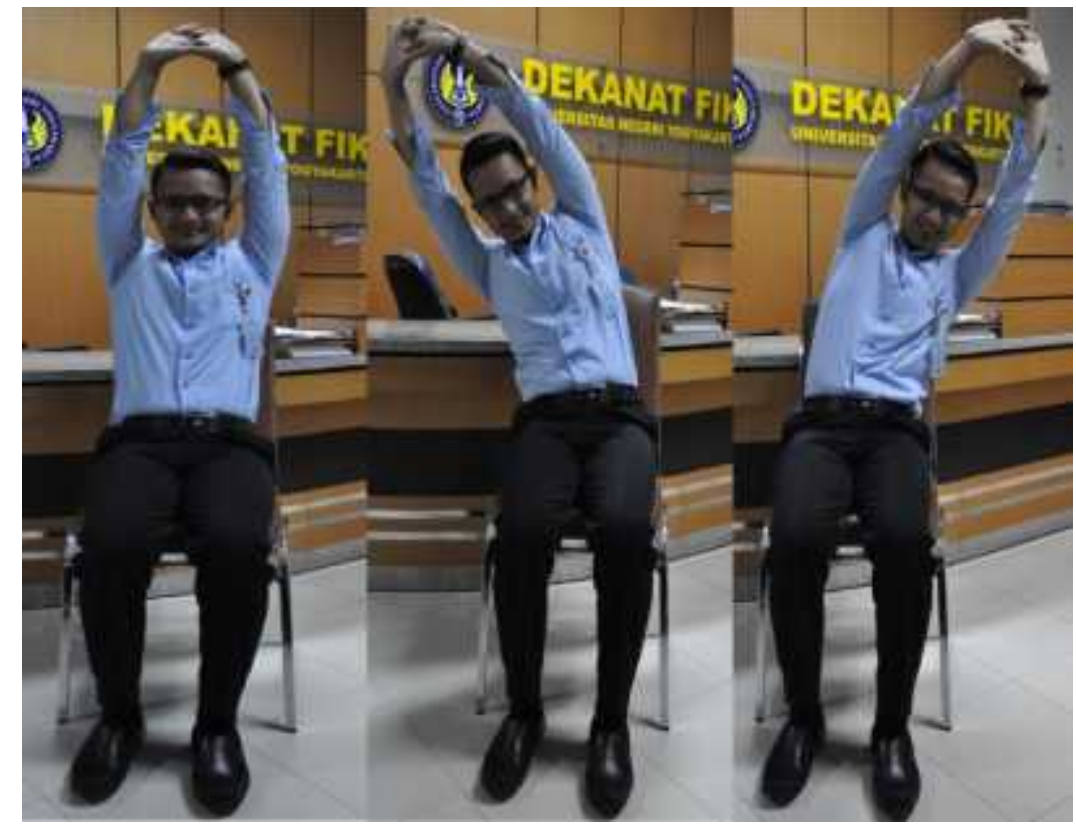

Gambar 3. Back side-stretch

Gerakan 4, middle back stretch

Tujuan : untuk membantu mengurangi kekakuan pada bagian bahu dan lengan

Cara pelaksanaan:

a. Duduk dengan punggung tegak,

b. Posisi kaki ditekuk rileks, selebar bahu

c. Pegang siku kiri dengan tangan kanan, lalu gerakkan dan dorong siku kiri ke arah pundak kanan. Tahan selama 5 detik

d. Ulangi untuk siku sebelah kanan

e. Ulangi gerakan 8-10 kali

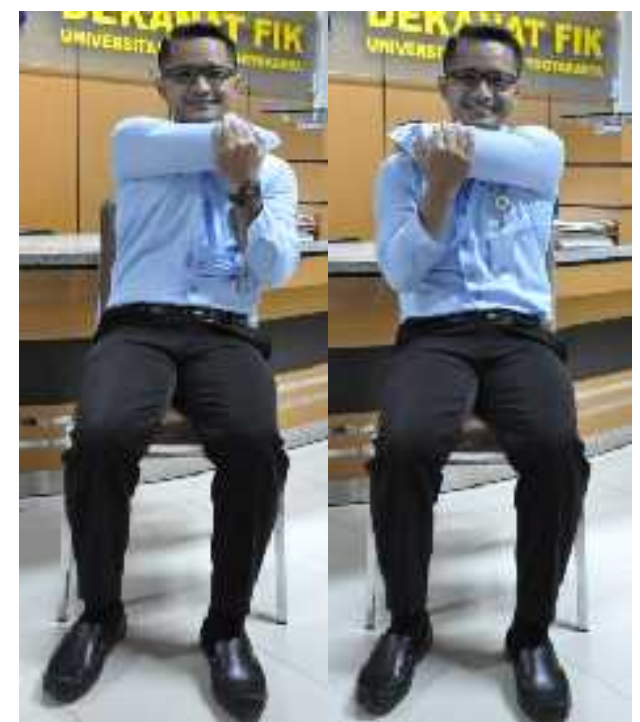

Gambar 4. Middle back stretch 
Gerakan 5, ankle flex and stretch:

Tujuan : untuk membantu mengurangi kekakuan pada bagian tungkai.

Cara pelaksanaan:

a. Duduk dengan punggung tegak

b. Angkat kaki kanan dari permukaan lantai

c. Gerakkan pergelangan kaki dengan cara mengarahkan ujung jari ke atas dan ke depan

d. Ulangi untuk kaki kiri

e. Ulangi gerakan 8-10 kali.

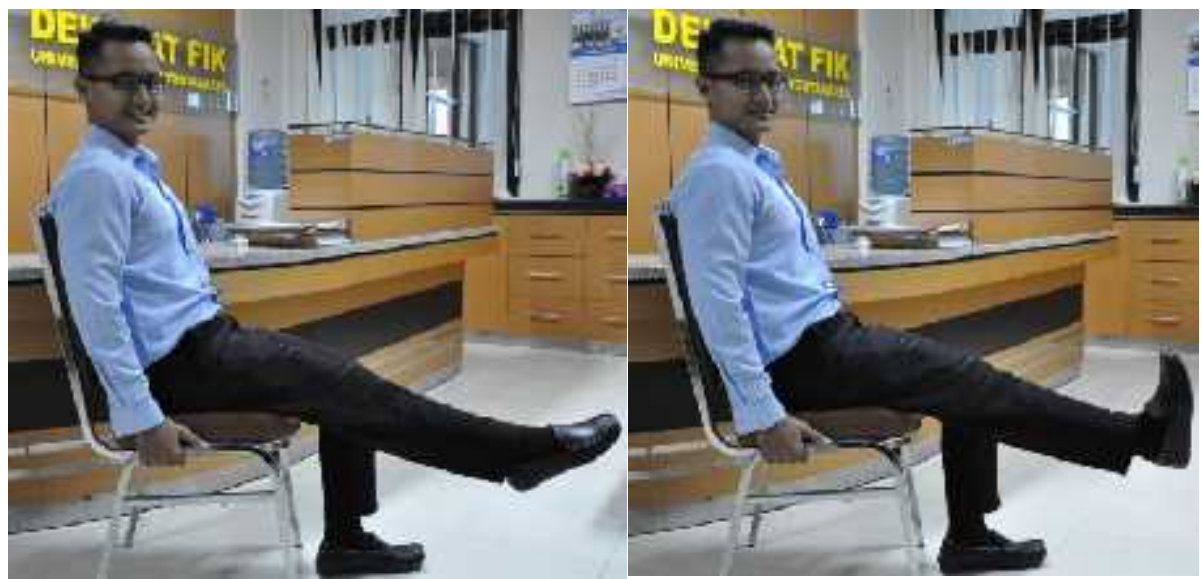

Gambar 5. Ankle flex and stretch

Gerakan 6,leg squats:

Tujuan : untuk membantu meregangkan dan membentuk otot pada bagian tungkai.

Cara pelaksanaan:

a. Berdiri tegak di depan kursi dengan posisi kursi berada di belakang Anda.

b. Turunkan tubuh sampai pantat hampir menyentuh kursi

c. Setelah itu, kembali bangun berdiri sebanyak 10 kali.

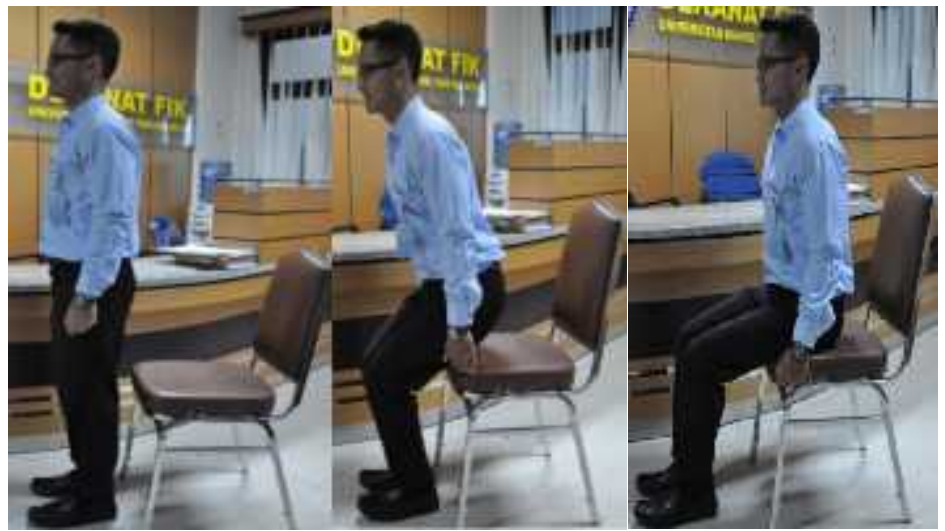

Gambar 6. Leg squats 


\section{Gerakan 7, bench dips:}

Tujuan : untuk membantu melatih otot pada bagian lengan, perut, dan tungkai.

Cara pelaksanaan:

a. Gunakan kursi atau meja yang kokoh dan tidak mudah digerakkan.

b. Berdirilah di depan kursi atau meja tersebut dengan posisi kursi atau meja berada di belakang Anda.

c. Letakkan tangan pada ujung kursi atau meja tersebut, lalu tekuk siku lengan untuk menurunkan tubuh secara perlahan hingga bagian bokong lebih rendah dari permukaan kursi atau meja.

d. Angkat kembali tubuh dengan meluruskan siku lengan, dan ulangi hingga 10 kali.

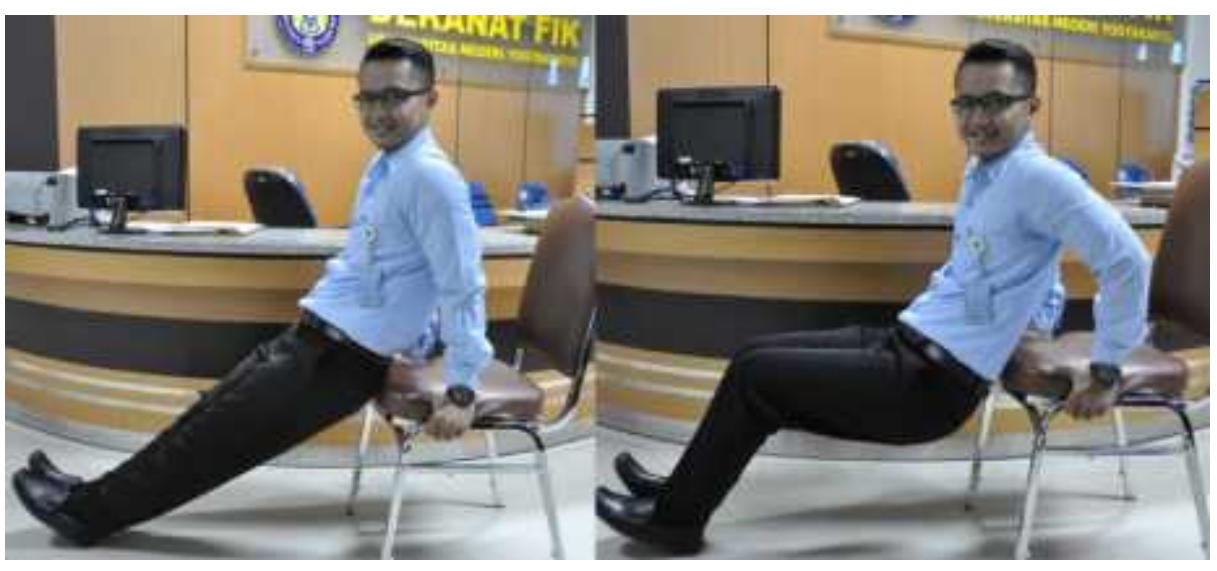

\section{Gambar 7. Bench dips}

Gerakan 8,push up:

Tujuan : untuk membantu melatih otot pada bagian lengan dan bahu.

Cara pelaksanaan:

a. Gunakan meja yang kokoh dan tidak mudah digerakkan, kedua telapak tangan menumpu pada meja.

b. Pastikan agar tubuh dalam keadaan lurus dan siku membentuk sudut 90 derajat dengan meja

c. Dengan bertahan pada posisi ini, tekuk salah satu lutut ke depan dan lakukan gerakan ini sebanyak 10 kali bergantian lutut kanan dan kiri.

d. Kemudian lanjutkan dengan gerakan push up sebanyak 5 kali dan ulangi serangkaian latihan ini sebanyak 8 sampai 10 kali perulangan 


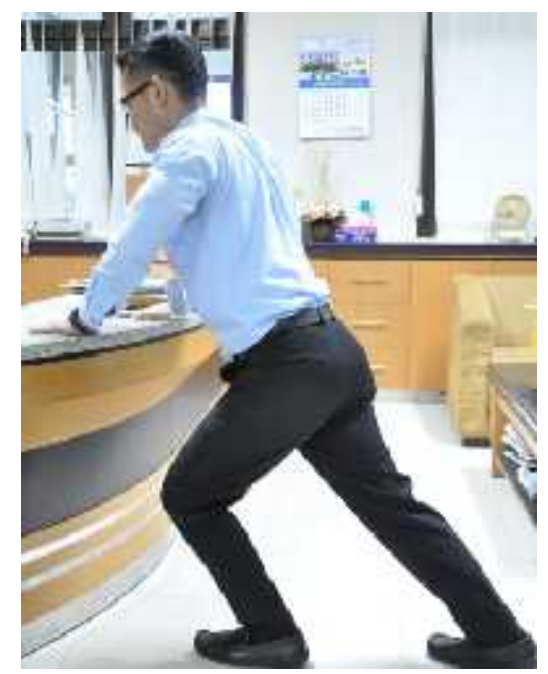

Gambar 8. Push up

Gerakan 9, aircraft poses:

Tujuan : untuk membantu melatih otot pada bagian tungkai, pantat, dan punggung. Cara pelaksanaan:

a. Gunakan meja yang kokoh dan tidak mudah digerakkan, kedua telapak tangan menumpu pada meja.

b. Kemudian angkat salah satu kaki ke belakang dan berdirilah dengan satu kaki.

c. Tarik kaki yang tidak menjadi tumpuan hingga memanjang ke belakang, sehingga dada sejajar dengan lantai membentuk posisi seperti pesawat terbang.

d. Tahan selama 3 detik sebelum kembali ke posisi awal, kemudian ulangi latihan ini selama 1 menit sebelum beralih kaki dan mengulangi gerakan yang sama dari awal.

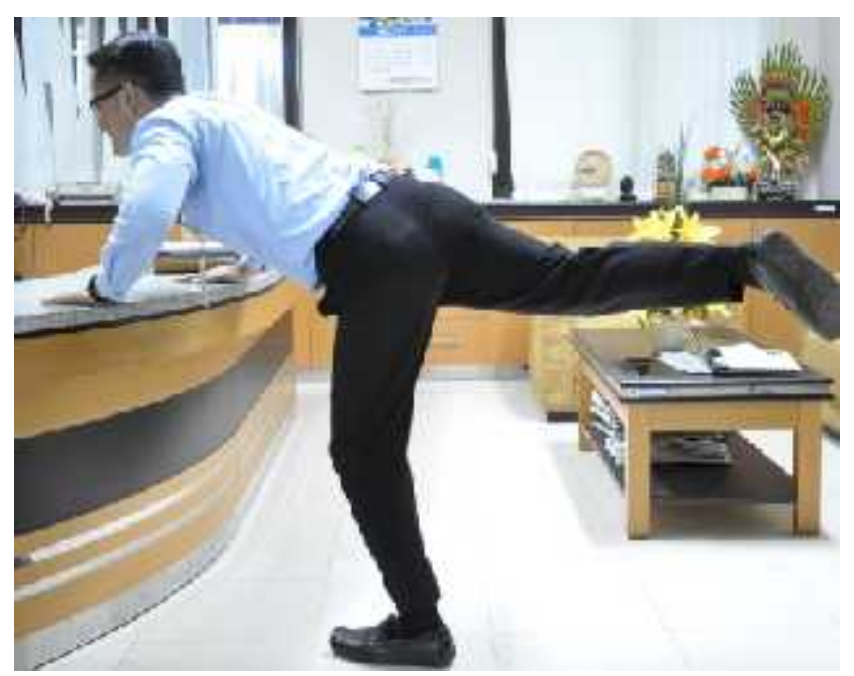

Gambar 9. Aircraft poses 
Gerakan 10, outer-iner:

Tujuan : untuk membantu melatih otot pada bagian tungkai, khususnya paha dalam dan paha luar.

Cara pelaksanaan:

a. Gunakan kursi yang tidak mudah digerakkan, duduk dengan punggung tegak dan rileks

b. Kedua tangan memegang kursi

c. Kedua tungkai di gerakan ke arah luar

d. Sebaliknya, kedua tungkai digerakan ke arah dalam

e. Ulangi gerakan 8-10 kali

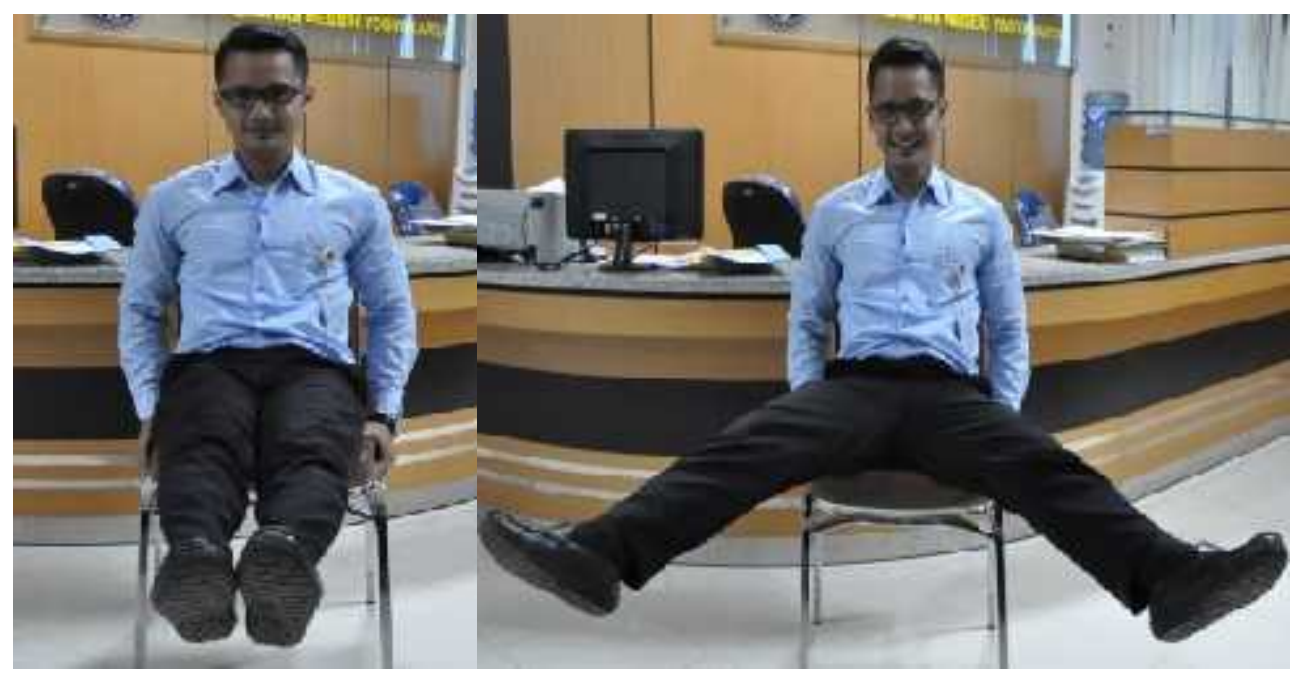

\section{Gambar 10. Outer-iner}

Untuk berolahraga, tidak selalu dibutuhkan alat khusus. Seseorang dapat memanfaatkan perlengkapan kantor, seperti kursi dan meja.Saat melakukan gerakan-gerakan olahraga di kantor, sebaiknya melepaskan sepatu hak tinggi yang dikenakan. Hal ini penting untuk mencegah agar tidak terjatuh atau mengalami cedera.

\section{Penutup}

Dampak yang timbul akibat tidak pernah berolahraga tidak hanya sebatas fisik saja, tetapi yang lebih ganas lagi bagi orang yang tidak mau aktif bergerak yaitu mudah terserang berbagai penyakit, seperti jantung koroner, tekanan darah tinggi, diabetes miletus, stroke, dll. Untuk itu, orang yang sesibuk apapun di kantor, harus senantiasa mensyukuri nikmat sehat karunia Allah SWT dengan memelihara dan meningkatkan melalui berbagai upaya, diantaranya yang terpenting, termurah dan fisiologis yaitu melalui olahraga. Gerakan-gerakan 
olahraga di atas sebagai contoh saja, untuk pengembangan agar olahraga tidak membosankan, seseorang dapat melakukan dengan gerakan variasi yang lain.

\section{Daftar Pustaka}

Anonim, 2014. Olahraga Untuk Orang Sibuk Cuma "2 Menit”. Diakses dari http://tipsehat4u.blogspot.com/2012/10/olahraga-2-menit.html, 3 April 2014.

Detiknews. Akibat Tidak Pernah Olahraga. Diakses dari http://www.fk.unair.ac.id/news/kilasan/akibat-tidak-pernah-olahraga-html, tanggal 5 April 2014.

Dhiah A.P. (2012). Olahraga Untuk Orang Sibuk. Diakses dari http://ayudani97.blogspot.com/2012/08/olahraga-untuk-orang-sibuk.html, tanggal 5 April 2014.

Santosa Giriwijoyo dan Muchtamadji M.A. (2006). Ilmu Faal Olahraga. Bandung: FPOK UPI.

Suharjana. (2004). Kebugaran Jasmani. Yogyakarta: FIK, UNY.

Vera Farah Bararah (2011). Ciri-ciri Fisik Orang Yang Tak Pernah Olahraga. detikHealth, diakses dari http://m.detik.com/health/read/2011/05/13/181738/1639410/766/ciri-cirifisik-orang-yang-tak-pernah-olahraga, tanggal 3 April 2014. 